\title{
Psicologia e Diversidade
}

\section{Psychology and Diversity}

\section{Psicología y Diversidad}

\author{
Neuza Maria de Fátima Guareschi \\ Universidade Federal do Rio Grande do Sul, RS, Brasil.
}

A revista Psicologia: Ciência e Profissão estabeleceu como uma de suas políticas a sua acessibilidade para pessoas com deficiência, tais como as de ordem visual, por exemplo. Para discutir formas de acesso da população com deficiência visual, bem como as tecnologias para a operacionalização desse acesso, apresentamos nesta edição um dossiê com cinco artigos de profissionais que nos auxiliam a refletir acerca das práticas de trabalho, da pesquisa, de intervenções sociais e na produção de conhecimento sobre a temática da acessibilidade.

Diante desse cenário, podemos pensar a forma como a acessibilidade tem sido conceituada. A Lei no 10.098, de 19 de dezembro de 2000, por exemplo, estabelece normas e critérios para promover a acessibilidade das pessoas com deficiência ou com mobilidade reduzida. De acordo com essa lei, a acessibilidade significa proporcionar às pessoas com deficiência as condições para alcançarem e utilizarem, com segurança e autonomia, os espaços, mobiliários e equipamentos urbanos, tais como as edificações, os transportes e os sistemas e meios de comunicação. Dessa forma, foi pensando na importância da garantia de direitos para pessoas com deficiência e destacando o caráter educativo e cultural que esta revista realizou um planejamento para aplicação da acessibilidade, bem como reconheceu a necessidade de buscar tecnologias competentes na área da informática para a que a própria revista Psicologia: Ciência e Profissão pudesse ser acessada também pela população com deficiência visual.

Pode-se dizer que em nenhum outro momento da sociedade, como no atual, o tema da diversidade foi tão mencionado. Diante disso, torna-se necessário pensarmos como ou por quem, em nome do quê ou para quem, a diversidade tem sido colocada como uma questão importante a ser tratada. Assim, além do dossiê que apresentamos nesta edição sobre o tópico da acessibilidade, publicamos também alguns artigos que remetem a diversos aspectos de populações e identidades como forma de propiciar reflexões mais amplas deste tema no campo da Psicologia.

A urgência em abordar a temática da diversidade se dá em razão de que, mesmo diante de práticas pautadas no respeito às diferenças, ainda no presente encontramos lógicas normalizadoras pautando ações direcionadas a populações específicas, seja no âmbito da saúde, da educação, da assistência, da segurança, da raça e da sexualidade, cujas intervenções, não raro, tendem a produzir, como efeito, sujeições às normas. Este debate, portanto, tem como proposta tensionar outras formas de produção de conhecimento, de práticas profissionais e de intervenções de pesquisa, que pensem o acesso e a efetivação de direitos, a partir da diferença entre os sujeitos.

Por meio dessa iniciativa, queremos chamar atenção a esse momento crítico do contemporâneo no qual as questões sobre as diferenças e diversidades têm sido simplificadas, naturalizadas e, até mesmo, banalizadas (Bhabha, 1998). Cabe mencionar que, mesmo quando pensamos em políticas de inclusão, o que está em jogo é a noção de diferença, sendo que, na maioria das vezes, o esforço dessas políticas é o de transformar esse outro diferente em igual ou em um mesmo, produzindo a naturalização da diferença como efeito. Spivak (2011) nos coloca que uma questão polêmica é também a de querer falar em nome 
daqueles que não têm voz ou que tenham alguma dificuldade para isso. A autora afirma, ainda, que, ao assumirmos essa posição de fala, contribuímos não criando espaço para outras vozes, mas, ao contrário, fazendo a manutenção da impossibilidade do outro falar, bem como com a manutenção de sua condição de subalternidade.

Sabemos que não é fácil falar sobre diferenças, diversidade ou políticas de inclusão no campo da Psicologia, devido às várias perspectivas teóricas e epistemológicas que fundamentam as práticas de pesquisa e intervenções profissionais. Embora todas as perspectivas possam se referir à garantia de direitos, ou intencionar mudanças sociais, estas possuem, também, diferentes concepções de sujeito.

Nesse sentido, é pela heterogeneidade de posições teóricas e ontológicas nas áreas de saber e nas práticas profissionais que destacamos a importância de garantirmos que as situações de opressão e exploração não sigam acobertadas em nossa sociedade, de modo que, frente a elas, possamos reagir individualmente, ou em coletivos, buscando os mecanismos de que dispomos para promover a saúde mental e física de populações minoritárias, ou pessoas de diferentes raças, etnias, orientação sexual ou condição social.

Diante de tal diversidade teórica e metodológica, apresentamos, neste número da revista Psicologia: Ciência e Profissão, 11 artigos que apresentam estudos relacionados às temáticas de violência, exclusão, diferenças culturais e sofrimento psíquico de populações negras, população em situação de rua e usuários de drogas.

Nesse sentido, o artigo que abre esta edição vem exatamente apresentar uma discussão sobre as associações que têm sido realizadas no âmbito de pesquisas da área médica e psicológica entre violência, fisiologia e anatomia. Tais associações se fundamentam em uma visão biologizante do mundo e se legitimam pelo discurso científico. O artigo "O Espectro Eugenista no Discurso Biodeterminista Contemporâneo", de autoria de Betina Hillesheim e de Mozart Linhares da Silva, tem como objetivo problematizar os aspectos epistemológicos e éticos abordando as articulações entre ciência e determinismo, bem como a emergência da eugenia no século XIX e seus deslocamentos até a contemporaneidade. Nessa, discutem que há uma centralidade da produção discursiva relativa ao cérebro, a qual implica também um modo de condução de condutas. A partir disso, evidenciam que, no século XXI, há um regime específico de biossegurança e bio- política em que a biologia deixa de ser compreendida como um destino e passa a ser vista como oportunidade. Tal modificação nas formas de entendimento implica uma série de novas lutas políticas em torno de uma economia da vida e, nesse cenário, tais pesquisas, com a justificativa de prevenção ao crime, configuram-se como estratégias de vigilância e controle sobre os corpos, especialmente daqueles sujeitos pertencentes a grupos minoritários.

Os próximos cinco artigos remetem à temática de identidades, referindo-se, direta ou indiretamente, a populações que passam por processos de exclusão/ inclusão. O primeiro destes artigos, de autoria de Jéssica Silva Rodrigues, Aluísio Ferreira de Lima e Renata Bessa Holanda diz respeito à população de rua. O artigo intitulado "Identidade, Drogas e Saúde Mental: Narrativas de Pessoas em Situação de Rua" teve por objetivo discutir como pessoas que vivem em situação de rua e que fazem uso abusivo de drogas lidam com os processos de exclusão social aos quais estão submetidos. Através da análise de narrativas desta população, sobretudo aquelas relacionadas à concepção de identidade enquanto metamorfose, personagem e as categorias mesmice e reconhecimento, pode-se perceber o impacto das formas de reconhecimento experienciadas na constituição de suas identidades, bem como as repercussões dos estigmas enfrentados por essas pessoas na representação cotidiana das personagens "pessoa em situação de rua" e "usuário de drogas". Já o artigo "Representações Sociais sobre Drogas: Estudo com Adolescentes em Conflito com a Lei", de autoria de Samkya Fernandes de Oliveira Andrade, Railda Sabina Fernandes Ahrs e Maíne Helen Pereira de Almeida Bassani, buscou conhecer e analisar as representações de adolescentes que cometeram atos infracionais acerca das drogas. A pesquisa foi realizada com 25 adolescentes em cumprimento de medida socioeducativa de internação, utilizando um questionário sociodemográfico e o Desenho-Estória com tema. O estudou apontou que "droga" foi representada negativamente, como sendo responsável por trazer consequências relacionadas a problemas de saúde e a conflitos familiares. O crack foi citado como sendo a droga mais destruidora, e é vinculada a atos delitivos para a manutenção do vício.

Outros dois artigos deste bloco de cinco tratam sobre identidades e inclusão/exclusão: um refere-se sobre saúde mental e racismo e o outro sobre concepções de professores em relação à surdez e o surdo. 
O primeiro deles, de autoria de Marizete Gouveia Damasceno e Valeska M. Loyola Zanello e intitulado "Saúde Mental e Racismo contra Negros: Produção Bibliográfica Brasileira dos Últimos 15 Anos”, objetivou realizar uma revisão sistemática na literatura científica brasileira sobre o impacto do racismo na saúde mental de negros no Brasil e verificar a contribuição da Psicologia nesse tópico. Foram considerados relevantes para análise 19 artigos, mesmo que não tratando exclusivamente do impacto do racismo na saúde mental. Observou-se que o racismo, como crença na superioridade de algumas raças sobre outras, justifica a desigualdade entre os grupos e é uma forma de ofensa. E estas são práticas que afetam a saúde mental da pessoa-alvo. Concluiu-se que o tema tem baixa produção acadêmica no Brasil de modo geral e pouca contribuição da Psicologia e, desta forma, para espaços de assistência social e serviços públicos de saúde mental, buscados majoritariamente pela população negra de baixa renda e dependente destes serviços. $\mathrm{O}$ artigo intitulado "Inclusão Escolar: Concepções dos Profissionais da Escola sobre o Surdo e a Surdez", de autoria de Carine Mendes da Silva, Rosa Monteiro, Danielle Sousa da Silva e Daniele Nunes Henrique Silva, apresenta como temática a inclusão educacional de surdos, debatida, especialmente, pela condição bilíngue e bicultural dos alunos, que exige práticas diferenciadas de ensino que partem da Libras. O objetivo do estudo foi entender o que os profissionais da escola dizem sobre o papel dessa língua. A pesquisa baseou-se na construção de dados organizados a partir de entrevistas semiestruturadas, seguindo os pressupostos teóricos do materialismo histórico dialético com profissionais de uma escola de ensino médio. As análises apontaram para a concepção dos profissionais sobre o surdo e a surdez na qual se evidencia que há uma lacuna na formação profissional dos educadores no que tange as especificidades dos alunos.

O último artigo deste bloco tem como objetivo analisar as dinâmicas de produção da identidade docente na Educação de Jovens e Adultos (EJA) nos primeiros anos de docência em duas capitais brasileiras. O artigo de autoria de Danyelle Natacha dos Santos Gois e Silviane Bonaccorsi Barbato, intitulado "Dinâmicas de Produção da Identidade Docentes na EJA", descreve uma pesquisa realizada com quatro professores atuantes na EJA da rede pública de ensino através de entrevistas. Os resultados indicaram que as dinâmicas de produção da identidade docente foram construídas em três temas centrais: Família, Formação Acadêmica e Mercado de Trabalho. As análises apontaram que a produção da identidade docente e profissional na educação de jovens e adultos nos primeiros anos de docência está em transição e é marcada por ambivalências geradas na dinâmica de permanências e mudanças em conflitos e incertezas, no presente, e expectativas de futuro relacionadas à continuidade da formação, a novas oportunidades de trabalho docente e uma educação mais significativa para o outro e para si.

O próximo artigo também trata do tema da diferença. De Adriana de Aguiar, Brigido Vizeu Camargo e Andréa Barbará da Silva Bousfield, ele tem por título "Envelhecimento e Prática de Rejuvenescimento: Estudo de Representações Sociais" e teve como objetivo identificar o conteúdo e a estrutura das representações sociais do envelhecimento e da prática de rejuvenescimento, a partir da abordagem estrutural das representações sociais. As participantes foram mulheres de meia-idade com atitudes favoráveis e contrárias a práticas de rejuvenescimento. Os resultados mostram que o núcleo central das representações sociais do envelhecimento é organizado em torno de perdas e ganhos, enquanto que o núcleo central das representações sociais da prática de rejuvenescimento remete a saúde, beleza e estados subjetivos. O estudo aponta que as representações sociais do envelhecimento e da prática de rejuvenescimento são ancoradas na ideologia do envelhecimento ativo e bem-sucedido, em que o bom envelhecimento não é apenas desejável, mas se estabelece como uma norma a ser seguida.

$\mathrm{O}$ artigo que apresentamos a seguir, "Análise de Luto de Mães de Crianças e Adolescentes Desaparecidos", discorre sobre violência, tema que tem sido bastante pesquisado nos últimos tempos no campo da Psicologia. De autoria de Gisleila da Silva Rolim, Letícia da Costa Radzeviaus, Mariana Fernandes Saldanha, Leila Salomão de La Plata Cury Tardive e Rodrigo Jorge Salles, ele teve por objetivo compreender o processo de luto de mães que desconhecem a localização e o motivo do desaparecimento do filho. As discussões realizadas apontam que as mães, devido às fantasias de não terem cumprido adequadamente seu papel, apresentam sentimentos de culpa e, para lidar com esses sentimentos, utilizam mecanismos de defesa cujo objetivo é evitar fatos e lembranças associados ao desaparecimento. Existem também complicações na reestruturação fami- 
liar decorrentes do desaparecimento, que, somadas a outros fatores, como o descrédito nas buscas, causam nas mães ambivalência entre o cansaço e a esperança de localizar o filho desaparecido.

O próximo artigo trata de um estudo empírico-instrumental realizado com uma amostra não probabilística com 510 trabalhadores, sendo que $54 \%$ destes eram mulheres. $\mathrm{O}$ artigo intitulado: "Pasión por el Trabajo: Evidencias de Validez Discriminante, Predictiva e Incremental", de Solana Salessi e Alicia Omar, teve por objetivo estabelecer a validade discriminante, preditiva e incremental da paixão pelo trabalho em relação ao flow, ao envolvimento e à satisfação no trabalho, respectivamente. Análises de regressão múltipla hierárquica confirmaram a contribuição significativa da paixão na explicação da satisfação pelo trabalho indicando que os resultados demostraram que a paixão pelo trabalho é um constructo teórica e empiricamente diferente, capaz de explicar atitudes organizacionalmente relevantes.

Pode-se dizer que o artigo que fecha a edição 38.3 deste periódico é um estudo que mostra como ações festivas de uma comunidade fortalece e mar- cam aquilo que os diferencia de outras populações. De autoria de Kamila Bezerra de Araújo e Marcelo Gustavo Aguilar Calegare, o artigo intitulado: "Os Festejos como Estratégia de Fortalecimento Comunitário em Comunidade de Manaus" teve por objetivo apresentar quais festejos já aconteceram na comunidade e seu significado para os moradores, para examinar como eles influenciaram o fortalecimento das redes comunitárias. A comunidade Parque Riachuelo I é localizada em Manaus/AM, existe há 40 anos e foi fruto de ocupações desordenadas. Está sediada na zona urbana, mas, como ainda não é plenamente urbanizada, apresenta também aspectos rurais. Os resultados do estudo apontam a lembrança de oito festejos marcantes, com o significado e a importância de promover engajamento e motivação nas lutas políticas, união, fortalecimento dos laços comunitários e sentimento de pertença. Os festejos se tornaram uma ferramenta estratégica para a união e lazer da comunidade, pois, a cada festa, mais moradores participam e dialogam sobre a sua comunidade, o que propicia maior fortalecimento comunitário.

\title{
Referências
}

Bhabha, H. K. (1998). O local da cultura. Belo Horizonte, MG: Ed. UFMG.

Lei no 10.098 , de 19 de dezembro de 2000. Estabelece normas gerais e critérios básicos para a promoção da acessibilidade das pessoas portadoras de deficiência ou com mobilidade reduzida, e dá outras providências. Diário Oficial da União. 20 dez 2000.

Spivak, G. C. (2011). Puede hablar el subalterno? Buenos Aires: El Cuenco de Plata.

\author{
Neuza Maria de Fátima Guareschi \\ Universidade Federal do Rio Grande do Sul \\ Editora \\ E-mail: neuza.guareschi@cfp.org.br
}

Como citar: Guareschi, N. M. F. (2018). Psicologia e Diversidade. Psicologia: Ciência e Profissão, 38(3), 409-412. https://doi.org/10.1590/1982-3703000032018

How to cite: Guareschi, N. M. F. (2018). Psychology and Diversity. Psicologia: Ciência e Profissão, 38(3), 409-412. https://doi.org/10.1590/1982-3703000032018

Cómo citar: Guareschi, N. M. F. (2018). Psicología y Diversidad. Psicologia: Ciência e Profissão, 38(3), 409-412. https://doi.org/10.1590/1982-3703000032018 